\title{
Chapter 12 \\ Concluding Discussion: The Past, Present, and Future of Technical Universities
}

\author{
Anders Broström, Lars Geschwind, and Katarina Larsen
}

In the introductory chapters of this volume, a few points of departure were outlined for the research efforts reported in this book. One was the lack of studies of this particular segment of the higher education landscape: technical universities as organisations. Further, this book offers a response to the call by organisational scholars for better understanding how organisational narratives affect identity formation, inertia, and actions in academic organisations (Gabriel 2004). It does so by addressing fundamental questions about the nature and identity of technical universities (Gioia et al. 2013; Stensaker 2015).

In the context of this volume, two broader questions were addressed in chapters on identity formation and boundary negotiations. First, how do organisations actively work with legitimacy-creating rhetorical strategies, which argue for change within the organisational field? Second, how do universities (specifically university leaders and other academics) think about categories such as 'technical university', 'research university', and 'vocational training institution', and what do these categories mean in relation to the organisational identity of a technical university in comparison with other higher education institutions?

The volume comprises contributions, which shed light on these issues, drawing on experiences from contemporary university landscapes. In some chapters, organisational identity — and particularly the identity category 'technical university' —is

\footnotetext{
A. Broström $(\bowtie)$

Department of Industrial Economics, KTH Royal Institute of Technology,

Stockholm, Sweden

e-mail: anders.brostrom@indek.kth.se

L. Geschwind

Department of Learning in Engineering Sciences, KTH Royal Institute of Technology,

Stockholm, Sweden

K. Larsen

Department of Philosophy and History, KTH Royal Institute of Technology,

Stockholm, Sweden

L. Geschwind et al. (eds.), Technical Universities, Higher Education Dynamics 56, 
the focus, whereas in others change as a consequence of external pressure and/or strategic action is foregrounded. In this concluding chapter, we discuss the findings from the empirical chapters in relation to the framework laid out at the beginning of the volume. Taking stock of lessons learned from the studies presented in this volume, we also discuss the potential futures of the technical university.

\subsection{Negotiating Boundaries and Relating to Identity Categories}

A first observation arising from the various examinations reported in previous chapters is that the organisational identity boundaries of contemporary HEIs are floating, and constantly challenged, tested, and negotiated within nested organisational fields (Wooten and Hoffman 2017; Hüther and Krücken 2016). This is discussed in the contributions by Schneijderberg, Carvalho and Diogo, Vellamo et al., and Antonowicz with examples from the German, Finnish, Portuguese, and Polish higher education sectors, respectively. Antonowicz provides an overview of technical universities in Poland and shows how status differences can play out at the national level. Despite constituting a large proportion of the sector, technical universities have not been recognised and highlighted as much as the multi-faculty, comprehensive universities. Carvalho and Diogo show that even in binary systems with formal division into two tiers, the boundaries between technically oriented universities and polytechnics are hard to define. An eye-catching example is the merger in Tampere, Finland between a technical university, a comprehensive university, and a polytechnic (a professionally oriented form of HEI in the Finnish two-tier system). Vellamo et al. discuss how the merger process offers interesting insights into the organisational identity of the technical university by triggering reflections on what unites and separates the technical university from the two other HEIs.

Boundary negotiations also take place within existing technical universities. The chapters of this volume give several accounts of boundary negotiations concerning the demarcation of a technical university from other advanced universities, in terms of curricula and subject areas. Antonowicz demonstrates how technical universities in Poland were tempted to abandon their focus on engineering subjects to participate in an expansion of education, focused on social science and humanities training, but how instead a path of preserving an existing disciplinary focus was chosen. Cronhjort and Geschwind demonstrate how teacher training was introduced at the two leading Swedish technical universities based on a mix of rationales.

Other important boundary negotiations take place between technical universities and institutions offering professional engineering education. Fagrell and Geschwind highlight a specific change initiative challenging such a boundary. The chapter describes how the Swedish government decided to incorporate the lower engineering education into higher education - until then at post-secondary school (gymnasium) level-and how this external 'shock' urged the technical universities to respond. 
The chapter by Edström also discusses the relationship between practical skills and theoretical knowledge, which is so important for the idea of a technical university. In contrast to Fagrell and Geschwind, however, the chapter describes an internal initiative to re-shape how these two aspects are integrated into teaching curricula. The chapter illustrates how engineering education is characterised by inherent tensions between identities and institutional logics from engineering practice and engineering science. This tension may play out differently in different organisations, depending on differences in organisational identity. For example, an HEI organisation strongly oriented towards engineering practice (such as a university of applied science/polytechnic) would tend to generate other compromises than a HEI strongly oriented towards academic values (cf Augier and March 2011). Under the premise that organisational identities of a technical university would tend to have somewhat different connotations than that of a technical faculty within a comprehensive university, we may expect technical universities to generate different compromises and solutions-possibly contributing to greater diversity within higher education systems.

\subsection{Strategic Responses to High Expectations}

The contributions in this volume also shed light on the complex interplay between internal and external stakeholders in contemporary higher education, and the expectations expressed from various perspectives (Geschwind 2019). It can be argued that such expectations, for example, expressed in terms of contributions to local economies, may play out differently in different HEIs. In particular, we see how the recognition of differences between HEIs (in terms of orientation towards different institutional ideals and differences in historical roots) helps to recognise and interpret institutional differences in the way that HEIs relate to contemporary debates on managerial tendencies in higher education (Deem et al. 2010), and on university organisations as strategic actors (Krücken and Meyer 2006). Associations to a tradition of application-oriented activities and close industrial relationships shape the idea of what it means to be a technical university. That identity and tradition also incorporate acceptance and (some) understanding of managerialist tendencies, derived from new public management sweeping over HEIs. The prevalent responsiveness to external actors, and willingness to adjust operations and organisational structures in relation to the technological development show that many universities identifying with the notion 'technical university' arguably are closer to being strategic actors, entrepreneurial, and enterprising HEIs than the average HEI-in particular in comparison with the ideal of the classic, comprehensive, European university (Etzkowitz 1988; Clark 1998).

So, how is the governance of technical universities evolving in a context of increased external expectations and demands for its services (Amaral and Magalhães 2002; Benneworth and Jongbloed 2010)? With more roles added to HEIs' core objectives affecting the day-to-day work of academic staff (such as time devoted to 
teaching, third mission, or commercialisation activities), the associated competing logics (Greenwood et al. 2011) warrant further analysis to understand conflicting goals within the organisation of relevance for career paths and policy for excellence and performance. The contribution by Benner focuses on the preconditions for three technical universities with seemingly similar contexts, in Sweden, Denmark, and Switzerland. The analysis shows that differences in management structures, funding arrangements, and recruitment patterns seem to have a significant impact on the research performance of the universities. Antonowicz shows how a strong organisational identity has helped technical universities in Poland to sustain in turbulent times, but also hampering renewal, innovation, and higher aspirations.

\subsection{A Position of Strength}

From the various analyses presented in this volume, it is clear that the category 'technical university' is associated with significant status. While some universities who think of themselves as technical universities are operating in the shadow of more brightly shining peer HEIs, being a technical university is nonetheless in many instances a source of a considerable degree of pride and confidence. Such status is both a function of a proud institutional history, and consistent support from important stakeholder groups. Qualified engineering and technical knowledge remains high in demand by students and industrialists alike, and is shaped by perceptions of what type of engineering knowledge fits the traditional mind-set for constructing physical infrastructures, software engineering, mathematic modelling biotechnology, and career paths in physics, chemistry and engineering. The traditional notion of engineering skills and 'hard' science and technology knowledge of engineering education continues to be perceived as a useful filtering mechanism for employers recruiting students with an engineering background, and as something of a 'rite of passage' for ambitious students. Networks of successful alumni consolidate the status of many leading technical universities, and in countries where the legal status so allows, provide an important source for funding raised from charity donation or similar activities.

Engineering education and technology research — and therefore HEIs championing these activities - have also enjoyed prioritisation from policy. This is clearly reflected in the chapter by Vabø and Langfeldt on NTNU in Norway, and in Schneijderberg's chapter on technical universities in Germany and how they have benefitted from the Excellence Initiative, for example. In some settings, a position of strength has also allowed technical universities to defend their position against the consequences of declining national budgets for higher education and research, as addressed in Antonowicz's chapter in this volume.

A position of strength (a strong identity and self-image) also implies a strong position that is considered worth preserving. This theme emerges clearly from the chapter by Fagrell and Geschwind, who describe how technical universities manoeuvred a situation of unwanted new responsibilities for what was previously 
vocational engineering education. It also surfaces clearly in Antonowicz's chapter, where he shows how Polish technical universities resisted a wave of diluting expansion affecting the sector in its entirety. Furthermore, the construction of Universities of Technology e. V. (TU9) in Germany, discussed in Schneijderberg's chapter, illustrates how networks and subfields are actively formed.

\subsection{Technical Universities: A Negotiated Ideal in Decline}

Having argued for the category 'technical university' being strongly embedded in many higher education systems, it might seem logical to predict that the focused technical university is a viable institutional template. Somewhat paradoxically, this prediction is not entirely congruent with empirical observations. As highlighted already in Chap. 2, many previously more focused technical universities have developed into more diversified HEIs. While some disappear through merger initiatives, others are transformed through a more slow-paced change, in the form of scientific bifurcation into other fields. Chapters in this book engage with universities such as NTNU in Norway, which has gone through a series of mergers with other types of HEIs, and TUT in Finland which at the time of writing is about to move away from a previous strong focus on engineering science and education through a merger. In the case of TUT this is also leading to an abandonment of the name 'technical university'.

A way to understand this development, in the context of the overarching analytical framework of the book, is that competing identity categories offer greater appeal. Specifically, it can be suggested that the category 'research university' is being perceived as an attractive alternative-as conveying a higher status in relevant stakeholder contexts-than the category 'technical university', drawing on previous studies about what these categories entails (Beerkens 2010; Martin 2012; Mohrman et al. 2008). The strategic direction for many universities seems to be geared towards accommodating further attributes associated with the research university, even at the expense of attributes associated with the technical university.

However, comparisons of experiences reported in the volume's different chapters also suggest the occurrence of interesting differences between national settings. In Chap. 8, Schneijderberg shows how a group of universities in Germany through their name and their membership in joint 'clubs' identify themselves as 'technical university', and how this category is associated with high status in the national context. Among the group of German TUs, we find some of the most prestigious research universities in the country. Meanwhile, Antonowicz, in Chap. 6, documents how in the neighbouring country of Poland, the group of HEIs referred to as technical universities have at least as much in common with the category that in certain countries is known as 'universities of applied science' (UAS) as they have with the idea of internationally active research universities. In Chap. 7, Carvalho and Diogo show that in one setting (Finland), policy makers were encouraged to maintain a binary system separating institutions for professional technical training 
from research-oriented technical universities. In another setting (Portugal), a group of international experts representing the same international body (the OECD) advised for the abolishment of such a binary system. Fagrell and Geschwind, finally, demonstrate that for two HEIs in Sweden identifying themselves as technical universities, the introduction of elements of professionally-oriented training into their curricula has given rise to some controversy.

It is possible to understand these findings as reflecting important differences between countries in how the relationship between the identity categories technical university and university of applied science are perceived. In contexts such as the German, Finnish or Swedish, the identity category technical university is associated with research-based teaching and world-class science. In Poland, Portugal and in other contexts, the same category is perceived as largely overlapping with the category 'professional training institutions'. It may be suggested that the presence of national champions in some countries (except for the above mentioned three, Chap. 2 identifies Denmark, the Netherlands and India as such countries) has charged the term 'technical university' with academic status. In the absence of such national champions, it has been possible for professionally oriented institutions to adopt the term in other settings, thereby generating national-level differences in the interpretation of a global script.

\subsection{So Who Is Responsible for the Demise of the Technical University?}

The aforementioned conditions for strength, together with the discussion about how the ideal of the technical university is changing, trigger questions about the reasons for this development and reactions either for or against change, while also acknowledging that technical universities have many things going for them. How can we understand this development? The student of the paradoxical disappearance of the technical university finds several clues to consider in the analyses contained in this volume. A number of 'suspects' may be identified, as follows:

1. The students (and their employers) are to blame. For decades, engineering education has included important elements of knowledge from non-engineering disciplines, such as economics, medicine, law, and management. In universities organised around such programmes, those with such broad scope are often amongst the most popular, and in universities where education is more modularised, the ability to include high-quality, non-engineering modules is often seen as increasing institutional attractiveness for students. This taste for variety in education among students is at least partially based on a favourable assessment of a mixed-skill education amongst employers. Furthermore, it has not been uncommon for policy-makers to encourage novel educational combinations of engineering education actively with other types of education. In Chap. 11 of this volume, Cronhjort and Geschwind analyse one such development, where new 
curricula integrating engineering and teacher education modules were introduced in response to national-level concerns about unsatisfactory recruitment into science and technology specialisations of existing teacher education programmes. In response to demand for a broad-based educational offering, it makes sense for universities, strongly dominated by science and engineering, to broaden their disciplinary scope. This pressure has most probably been particularly strong for universities based in non-metropolitan locations, where diversification through collaboration with local universities is not possible, and where regional expectations and ambitions are centred on one or very few universities. The recent history of the Norwegian University of Science and Technology (NTNU)_-described in Chap. 4 of this volume-offers an illustrative example of such processes (see also Brandt and Nordal 2010).

2. The American universities, and the success of their institutional templates, are to blame. While technical universities_-built on the foundations of nineteenth century polytechnic schools - still play a prominent role in the European university landscape, the leading institutional role models of the twentieth and twenty first century are found on the other side of the Atlantic. And while (for example) the Massachusetts Institute of Technology (MIT) and the California Institute of Technology (Caltech) are technical universities in name, they have developed from traditions and institutional models different from others such as Delft University of Technology and the Swiss Federal Technical University (ETH) in Zürich. As outlined in Chap. 2 of this volume, American universities were historically modelled on the British college, and the North-American higher education system has long been characterised by a strong tradition of 'liberal arts' education. Celebrated American universities with a strong focus on technology and its commercial and societal consequences (such as Stanford and MIT) also take pride in hosting world-class scholarship in the arts (humanities) and in social sciences. As leading role models for ambitious university leaders and politicians across the world, these institutions exercise significant mimetic influence on strategies for (present and previous) single-faculty technical universities across the world. Bearing in mind that European models of the technical university and national idiosyncratic understanding of engineering education are inspired by a model with strong emphasis on elements of liberal arts, the singlefaculty technical universities are experiencing something of a transformation, creating debates and discussion of core identity and values for technical universities. Other processes, such as mergers of universities, are further amplifying this debate internally.

3. University leaders are to blame. Students of mergers, acquisitions, and diversification in private industry have long suspected that a substantial share of such activity is driven by the potential benefits of current managers, rather than those of owners and other stakeholders. University leaders are subject to similar temptations. Being a rector of a large university is more prestigious than a similar job at a smaller institution. Leading a growing organisation can often be more stimulating than the job of managing a stagnated or even contracting organisation. A leader of a specialised technical university, who perceives that the only road to 
budget and activity increases goes through a merger with another HEI-or through diversifying the existing portfolio of activities-will think twice before foregoing such opportunities. Not least because the budget of a broader, more diversified university is less sensitive to future changes in funders' priorities, student tastes, and scientific trends. Further, it may be markedly less fun to be a rector of a university, which is forced to navigate a budgetary decrease, than to run an organisation, which can use its weight and breadth to sail safely through stormy waters. For these reasons, university leaders may find it in their interest to leave a focused profile behind and develop their institution towards a more full-breadth type of university.

4. The producers of university rankings are to blame. The practice of collecting, weighting, and aggregating data into more or less comprehensive ranking lists of universities has flourished during the last two decades (Shin et al. 2011). Through their conceived importance for the prestige of ambitious mid-level universities in the eyes of students, faculty, politicians, and the international academic community, rankings have moved into focus for university leaders worldwide. Moreover, what means does a rector have to act on the university board's strategic directive to ensure positions gained in some of the most important rankings? What policy can the aspiring political reformer push forward to have local universities rise to more prominent ranking positions? A quick analysis of how these rankings are constructed will convince the decision-maker that gaining size is the most viable option. And how does a focused technical university achieve this purpose? Most often, the answer will be to merge with the local comprehensive university (like in Lisbon 2013), the local research institute (like in Karlsruhe 2009), the other local specialised universities (like in Helsinki 2010), or a combination of these. A university leader, seeking to defend the continued existence of an independent technically focused university, must argue why this option is worth the risk of being surpassed by several competitor institutions in the status-laden international benchmarking tools into which ranking lists have developed.

5. The bureaucrats are to blame. Defenders of ivory-tower ideals, faculty unions, and countless professors do not hesitate to point to the efficiency-oriented bureaucrats of governments and university administrations as the sources of many evils befalling universities. In pursuit of scale economies and increased budgetary efficiency, some universities have been subjected to considerable reform. From an efficiency-maximisation perspective, mergers and diversification often make perfect (theoretical) sense. Under a joint organisational umbrella, different types of education may achieve more optimal resource utilisation, for example, by sharing facilities or service functions. Although perhaps not outright decisive, such considerations may add weight to arguments for diversifying university mergers or a major diversification initiative. 


\subsection{Does Disciplinary Focus Build Strong Brands?}

In seeking suspects behind the trend of widespread disappearance of disciplinaryfocused technical universities, the alert reader may have noticed that there is one important stakeholder group not yet mentioned. Analyses presented in the book have provided no clear indications as to how engineering faculties perceive the pros and cons of engineering science and education being performed in a focused technical university - as opposed to a university with a more multi-disciplinary character.

In Chaps. 1 and 2, we have already argued that science and engineering, (while conceived as different academic disciplines) have a great degree of overlap, and that only very few universities are able to excel in engineering research without also being strong in the natural sciences. However, what is to gain (or lose) for a university by broadening the scope beyond these two subject areas? In particular, does the co-location of science, technology, and engineering research with other academic disciplines under the same virtual roof affects the status and prestige of research and education, compared to constituting a stand-alone technical university?

For the sake of argument, let us consider an academically strong faculty of engineering. How would the reputation of this faculty be affected within the confines of a comprehensive university with equally strong faculties representing other disciplines, as compared to a faculty operating within a focused technical university? It could be reasonable to expect that comprehensive universities enjoy positive prestige spill over effects between strong faculties. Academic peers and other stakeholders, according to this view, would assign a status premium to an engineering faculty, due to the existence of positive associations. However, it could also be that focus is rewarded with positive prestige effects. This would be the case if peers and stakeholders more clearly associate a university with excellence in science and technology if the university is dedicated to activities within these domains.

To assess this question, let us visit a list of universities ranked as the most prestigious in engineering and technology (E\&T). Table 12.1 is based on the QS ranking (specifically, the 'QS World University Rankings by Subject'). It is possible to exploit the underlying data of this ranking to investigate to what extent the prestige of each university (in each subject area) is inflated or depreciated, relative to objectively observable metrics, such as the volume of scientific output and the level of

Table 12.1 Reputational effects in the area engineering \& technology, for universities top-ranked in that area

\begin{tabular}{l|l|l|l}
\hline & $\begin{array}{l}\text { All universities top-ranked } \\
\text { in E\&T }\end{array}$ & $\begin{array}{l}\text { Universities top-ranked across } \\
\text { subject areas }\end{array}$ & $\begin{array}{l}\text { Focused technical } \\
\text { universities }\end{array}$ \\
\hline Research reputational effects & \\
\hline Positive & $28 \%$ & $22 \%$ & $43 \%$ \\
\hline Negative & $20 \%$ & $17 \%$ & $29 \%$ \\
\hline Education reputational effects & $28 \%$ \\
\hline Positive & $24 \%$ & $22 \%$ & $71 \%$ \\
\hline Negative & $48 \%$ & $39 \%$ &
\end{tabular}


citations to works authored at each university. It thereby becomes possible to assess whether focused technical universities are more or less likely than broad universities with world-class activities in several areas to be subject to positive and negative reputation effects, respectively. For example, if positive reputation spill over benefits between scientific areas exist, we would expect universities with top-ranked positions in many disciplines to have their reputation and prestige in engineering inflated beyond what would seem to be motivated from the point of view of their scientific output only. If, on the other hand, a narrower profiling helps a university nurture its brand among peer scientists and other stakeholders, we should expect to find positive reputational effects to be more common among the focused technical universities in the ranking list.

We construct two reputation effect measures based on the underlying data of the QS ranking. This ranking draws on two surveys, which assess the reputation of a university. The first survey is directed towards university faculty, and asks about research prestige. The second targets employers, and asks from which universities employers are most happy to recruit. Based on the two surveys, each university is assigned a score (ranging from 0-100) for each focused subject and (broader) subject area. Publication and citation data from the Scopus database are used to produce a third score with the same range.

Based on this data, we construct measures of reputational effect by comparing reputation scores with the score based on publications and citations. We consider a university to enjoy a positive reputation effect within a subject area if it scores decisively higher for reputation than is scores for publications and citations within that area. Specifically, we refer to a positive research reputation effect when the score (based on peer assessments in the faculty survey) is $>5 \%$ higher than the score based on publication and citations. A positive education reputation effect correspondingly occurs when the score based on the employer survey is $>5 \%$ higher than the university's publication and citations.

Table 12.1 presents the share of the 25 universities that are top-ranked in the engineering and technology subject area, for which we find such reputation effects. While column 1 shows results for all 25 universities, columns 2 and 3 show results for two sub-groups of universities. The first of these are the 18 universities that are top-ranked in E\&T, but also in both natural sciences and social sciences. The rightmost column lists results for the seven universities that (while identified as excellent in engineering and technology) were not also identified as such in both the natural sciences and in the social sciences. These are EPFL, Tokyo Institute of Technology, Politechnico di Milano, TU Delft, Universiti Malaya, Georgia Tech, and TU Munich-all traditionally profiled technical universities.

The first row of column 1 shows that $28 \%$ ( 7 out of 25 universities) score higher for research reputation than for publication output. Such positive research reputational effects are, as shown by comparing columns 2 and 3 of the same row, more common among the focused universities. Overall, the focused universities are found to be more eligible to reputational effects in both directions. The most striking result, however, is that we find negative reputational effects for $71 \%$ of the focused universities. Together, these results would seem to suggest that while a focused 
Table 12.2 Reputational effects in the area social sciences, for universities top-ranked in the area engineering \& technology

\begin{tabular}{l|l|l|l}
\hline \multicolumn{1}{|l}{$\begin{array}{l}\text { All universities top-ranked } \\
\text { in E\&T }\end{array}$} & $\begin{array}{l}\text { Universities top-ranked across } \\
\text { subject areas }\end{array}$ & $\begin{array}{l}\text { Focused } \\
\text { universities }\end{array}$ \\
\hline \multicolumn{2}{l}{ Research reputational effects } \\
\hline Positive & $44 \%$ & $50 \%$ & $33 \%$ \\
\hline Negative & $28 \%$ & $17 \%$ & $67 \%$ \\
\hline Education reputational effects & \multicolumn{2}{|l}{} \\
\hline Positive & $64 \%$ & $72 \%$ & $50 \%$ \\
\hline Negative & $16 \%$ & $6 \%$ & $50 \%$ \\
\hline
\end{tabular}

profile may help a prominent technically oriented university build credibility in the eyes of its academic peers, it does not generally increase the status of their engineering students in the eyes of employers.

A similar exercise regarding the activities in the social sciences by the same group of universities (presented in Table 12.2) reveals a rather striking pattern. For the group of broader universities, positive reputational effects dominate. This suggests the presence of positive reputational spill over effects between subject areas in a strong, broad university, such as MIT or the University of Cambridge. However, social scientists active at the focused technical universities tend to enjoy lower credibility from their social science peers than what would seem to be motivated by their actual scientific production. This finding suggests a strategic challenge for focused technical universities such as DTU, the Technical University of Denmark, or TU Delft, in the form of a reputation barrier that may inhibit them from being recognised for excellence outside their traditional science and engineering areas.

In conclusion, data from two global reputation surveys suggest that being a focused technical university helps maintaining a strong brand among the global community of engineering faculties. However, focused technical universities also seem to be subject to reputational lock-in effects, in that the quality of social science performed at focused technical universities is underestimated by social science peers. These tendencies may be understood as reflecting prevailing ideas about the identity category technical university, and what types of qualities such a university is known for. If seen in that light, it is interesting to note that a branding strategy based on maintaining focused excellence does not seem to appeal to wider groups of the universities' stakeholders (here represented by potential employers of engineering graduates).

\subsection{Strategic Responses to Changing Ideals}

In this volume, we have devoted ourselves to the study of past and present events, which we suggest each have something to say about the organisational identity category 'technical university'. When working their way through this volume, the 
readers have probably asked themselves what can be learnt about the future of the technical university as an ideal, and about the future of contemporary higher education institutions relating to this ideal. Do the lessons we think we have learnt, as summarised earlier, allow us to also glimpse into the future of this category? More specifically, in what ways will it remain a useful point of reference for an ambitious HEI to think of itself, and communicate itself, as belonging to a category of organisations known as technical universities? Should leaders of more focused technical universities seek to stand up against the numerous trends through which so many focused technical universities have been transformed? Should champions of engineering education fight for the preservation and possible re-invigoration of the focused technical university? Should new technical universities be created in a future wave of foundation, institutional upgrading, and organisation of universities?

In reflecting on questions such as these, the theoretical perspectives developed in this volume offer useful guidance. In particular, adopting a perspective based on categories of organisational identity allows us to work around discussions of whether a particular university is to be understood as belonging to an organisational sub-field referred to as 'technical university'. Thinking about the same notion as a category of organisational identity allows for a more nuanced discussion, because it follows natural from this perspective to think of organisations as relating to several, possibly nested categories of organisational identity. It also becomes natural to aggregate empirical observations from several organisations, such as we do in this chapter, to consider the category as such. For example: What gestalt must such a category take to be attractive?

This question gives rise to some final reflections about what types of strategies technical universities apply to address both immediate 'threats' of change (discussed previously) and what attributes a category like technical universities need in order to stay relevant and agile to address contemporary challenges and expectations from both industry and society. The chapters in this volume contribute with some examples of such strategies, drawing on studies of strategies of higher education institutions to adapt, influence, avoid, and resist (Gornitzka 1999; Geschwind 2010), but also some strategies including:

- Redefining the boundaries for their activities as a technical university by using the historical legacy of the university (or its ancestors) or arguing for renewal by organisational change through mergers or restructuring.

- Identity agility strategies, including deliberate use of different identities and categories of logics to enable a more flexible way to cope with change introduced externally, through national reforms or introduction of international templates (assessment indicators etc.).

- Further developing and enforcing industrial relations to stay relevant to societal expectations.

Alternative strategies, for example, would be increased independence and autonomy towards industry; however, given the historical ties to industry, such a development is not something we see on the horizon or can detect in the chapters contributing 
to this volume. Rather, the organisational identities we can detect draw on the creation of counter-narratives about the other (non-technical) universities as an active way of constructing the own identity. Discussing future paths for the technical university as an institutional template and organisational identity category brings us to discuss some broader questions about their position in relation to comprehensive universities and the expansion of the HEI sector, as well as how new identities can evolve during processes of organisational change. This is discussed in the chapter by Vellamo et al. in terms of identity as a collective social concept, where group membership is important; hence, emphasising the category of technical university as important. Conversely, standing out within a field of technical universities and creating a strong identity narrative that is easily communicated is of importance to most HEIs to maintain a distinct profile and argue their relevance to society. Drawing on analysis of sameness and difference, another strategy is to form alliances with similar HEIs in the same category or institutional field of technical universities. Being included in a similar context reaps benefits of belonging to a field (or herd) of technical universities, but nevertheless cultivates a distinct profile and identity to stand out. Another contribution to this debate is made in the chapter by Antonowicz, discussing the tensions between growing popularity of global university rankings and their influence on HE policy and technical universities preserving their unique identity.

Outlining some avenues of further research, there are several areas that seem promising, based on the findings and analysis in this volume. One area concerns how technical universities work internally with strategies, which argues for change within the organisational field. In the light of processes of mimicking existing models of technical universities, and for engineering education (including of liberal arts components in the US and other models based on single-faculty technical universities) we recognise that there are several ideals existing at one point in time. This provides ample opportunity for further studies of both national empirical contexts and indepth analysis of mechanisms for transformation and resistance to change. A related question concerns 'field membership' and how counter narratives voiced by technical universities (contrasting their activities, status and ideals to other HEIs) will be orchestrated in the future. On the one hand, merger processes challenging existing ideals of technical universities can be expressed as diluting an ideal of the singlefaculty technical university and bring about strategies for resisting change. On the other hand, the alternative is that this very same process can lead to debates about enriching existing models to cope with future challenges of technical universities.

\subsection{A Roadmap for Developing the Idea of a Technical University}

We (the editors of this volume) are all currently active as researchers and teachers at a university which calls itself an 'institute of technology'; a term that we see as largely synonymous with 'technical university'. It is, therefore, natural to us at the end of the volume and the journey that was the writing of it, to also offer slightly 
more personal reflections on the lessons learned. We, and hopefully our readers, are most interested in trying to take stock of what roads lie ahead that seem the most attractive for the technical universities of today.

As we have argued, many technically oriented universities approach their future with confidence, with the pride that is derived from a strong historical legacy, and from strong support from large parts of society. Technology, the domain of expertise claimed by these institutions, is more pervasive than ever. This situation offers highly interesting opportunities. However, the tremendous penetration of technological artefacts into modern lives and industries does not guarantee the relevance of existing technical universities for the educational and scientific needs of tomorrow. Neither can we conclude that the key importance of technology in itself motivates an organisation of engineering education and technical research in the form of the 'classical' technical university, as envisaged in Europe. We may even feel compelled to argue that the observation that technology has moved into the very centre of society leads to the conclusion that organisational templates dating from previous industrial and technical revolutions need to be updated.

It is our impression that European universities have for a long time been relatively loath to think seriously about picking up some of the key traits of the successful American variant of the technical university - a variant that places less emphasis on engineering orthodoxy. This is probably a consequence of institutional inertia derived from the organisational principles of universities as such, but also a consequence of strong embeddedness in national and inter-European contexts.

As we have noted, more recent years have seen increased activity in re-thinking the boundaries and organisation of technically oriented universities. Does that mean that the broad research university is the only viable institutional template for building the leading HEIs of tomorrow? Are both the heritage and tradition of technical universities to be understood as liabilities? We would argue that this is not the case. The identity category 'technical university' is associated with values and ideas, which we are sure have an important role to play for higher education and for academic research. These values can be mobilised in the building and rejuvenation of academic institutions.

In our view, the engineering mind-set constitutes one such value. Higher education institutions, whose organisational identities are soaked in the problem-oriented approach of engineering practice, are likely to play important roles in the academic landscape of tomorrow, developing novel, innovative solutions in research and education. The focus on, and the genuine fascination for, the opportunities and risks of new technology also constitute an organisational principle that we believe many HEIs currently or historically referring to themselves as 'technical universities' will be able to refine and build successful strategies from. This also entails strategies for actively recognising societal expectations for new technological solutions to acknowledge users' impact on shaping novel technology-not only technology change influencing the daily life of users, industrial sectors, and society broadly. In shaping such strategies, university leaders are, we would argue, well-advised to define what it means to them to be the leader of a technical university. In this exercise of key relevance are questions such as what humanity needs and wants (and, in 
a slightly more mundane spirit, the objectives of present and future industry, government, and other stakeholders) to know and do to harness the potential of continued technological development. Defining the technical university as an institution dedicated to the existing subjects that constitute engineering science, without recognising future demands of responding to even more complex challenges, means we will risk missing valuable opportunities to grow the next generation of technical universities. Another concern pertains to a how a more fluid notion of technical university organisations influences the understanding of future needs of key engineering skills, as they are being negotiated within and between organisational boundaries of what we today call a technical university.

\section{References}

Amaral, A., \& Magalhaes, A. (2002). The emergent role of external stakeholders: European higher education governance. In A. Amaral, G.A. Jones, \& B. Karseth (Eds.), Governing higher education: National perspectives on institutional governance (pp. 1-21). Dordrecht: Springer.

Augier, M., \& March, J. G. (2011). The roots, rituals and rhetorics of change. North American business schools after the second world war. Stanford: Stanford University Press.

Beerkens, E. (2010). Global models for the national research university: Adoption and adaption in Indonesia and Malaysia. Globalization, Societies and Education, 8(3), 369-381.

Benneworth, P., \& Jongbloed, B. W. (2010). Who matters to universities? A stakeholder perspective on humanities, arts and social sciences valorisation. Higher Education, 59(5), 567-588.

Brandt, T., \& Nordal, O. (2010). Turbulens og tankekraft: historien om NTNU. Pax.

Clark, B. R. (1998). Creating entrepreneurial universities: Organizational pathways of transformation. Bingley: Emerald Group Publishing Limited.

Deem, R., Hilliyard, S., \& Reed, M. (2010). Knowledge, higher education, and the new managerialism. Oxford: Oxford University Press.

Etzkowitz, H. (1988). The making of an entrepreneurial university: The traffic among MIT, industry, and the military, 1860-1960. In E. Mendelsohn, M. R. Smith, \& P. Weingart (Eds.), Science, technology and the military. Sociology of the sciences (a yearbook) (Vol. 12/1/2, pp. 515-540). Dordrecht: Springer.

Gabriel, Y. (2004). Myths, stories, and organizations: Premodern narratives for our times. Oxford: Oxford University Press.

Geschwind, L. (2010). Getting pole position: Research strategies in the humanities at Swedish universities. Tertiary Education and Management, 16(2), 115-127.

Geschwind, L. (2019). Legitimizing change in higher education: Exploring the rationales behind major organizational restructuring. Higher Education Policy, 32(3), 381-395.

Gioia, D. A., Patvardhan, S. D., Hamilton, A. L., \& Corley, K. G. (2013). Organizational identity formation and change. The Academy of Management Annals, 7(1), 123-193.

Gornitzka, Å. (1999). Governmental policies and organisational change in higher education. Higher Education, 38(1), 5-31.

Greenwood, R., Raynard, M., Kodeih, F., Micelotta, E. R., \& Lounsbury, M. (2011). Institutional complexity and organizational responses. Academy of Management Annals, 5(1), 317-371.

Hüther, O., \& Krücken, G. (2016). Nested organizational fields: Isomorphism and differentiation among European universities. In E. P. Berman \& C. Paradeise (Eds.), The university under pressure (pp. 53-83). Bingley: Emerald Group Publishing Limited.

Krücken, G., \& Meier, F. (2006). Turning the university into an organizational actor. In G. S. Drori, J. W. Meyer, \& H. Hwang (Eds.), Globalization and organization: World society and organizational change (pp. 241-257). Oxford: Oxford University Press. 
Martin, B. R. (2012). Are universities and university research under threat? Towards an evolutionary model of university speciation. Cambridge Journal of Economics, 36(3), 543-565.

Mohrman, K., Ma, W., \& Baker, D. (2008). The research university in transition: The emerging global model. Higher Education Policy, 21(1), 5-27.

Shin, J. C., Toutkoushian, R. K., \& Teichler, U. (Eds.). (2011). University rankings: Theoretical basis, methodology and impacts on global higher education. Dordrecht: Springer.

Stensaker, B. (2015). Organizational identity as a concept for understanding university dynamics. Higher Education, 69(1), 103-115.

Wooten, M., \& Hoffman, A. J. (2017). Organizational fields: Past, present and future. In R. Greenwood, C. Oliver, T. B. Lawrence, \& R. E. Meyer (Eds.), SAGE handbook of organizational institutionalism (pp. 55-74). London: SAGE.

Open Access This chapter is licensed under the terms of the Creative Commons Attribution 4.0 International License (http://creativecommons.org/licenses/by/4.0/), which permits use, sharing, adaptation, distribution and reproduction in any medium or format, as long as you give appropriate credit to the original author(s) and the source, provide a link to the Creative Commons license and indicate if changes were made.

The images or other third party material in this chapter are included in the chapter's Creative Commons license, unless indicated otherwise in a credit line to the material. If material is not included in the chapter's Creative Commons license and your intended use is not permitted by statutory regulation or exceeds the permitted use, you will need to obtain permission directly from the copyright holder.

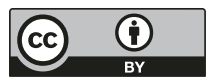

